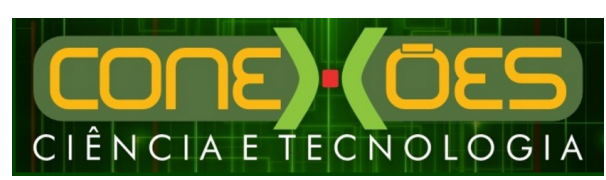

DIRETRIZES BÁSICAS PARA ELABORAÇÃO DE SISTEMA DE GESTÃO AMBIENTAL EM EMPRESA DE SUPERMERCADOS

\title{
DIRETRIZES BÁSICAS PARA ELABORAÇÃO DE UM SISTEMA DE GESTÃO AMBIENTAL EM UMA EMPRESA DE SUPERMERCADOS
}

\author{
Francisco Bruno Monte Gomes ${ }^{1}$, Priscilla de Paiva Sousa ${ }^{1}$, \\ Anna Kelly Moreira da Silva ${ }^{1}$, Aline de Carvalho Oliveira ${ }^{1}$ \\ ${ }^{1}$ Instituto Federal de Educação, Ciência e Tecnologia do Ceará, Campus de Sobral \\ <bruno06gomes@gmail.com>, <gomesdebruno@ hotmail.com> \\ <annakelly@ifce.edu.br>, <alinecaroli@gmail.com> \\ DOI: $10.21439 /$ conexoes.v11i3.879
}

\begin{abstract}
Resumo. As questões ligadas ao meio ambiente têm ganhado espaço dentro das empresas, seja devido ao interesse no retorno financeiro proporcionado pelo reaproveitamento de resíduos ou pelo crescimento da conscientização ambiental dos seus consumidores, de acordo com pesquisas do Ibope e da Confederação Nacional da Indústria revelaram que $68 \%$ dos consumidores brasileiros pagariam mais por produtos que não agredissem o meio ambiente. Com tudo isso, para manterem-se no mercado competitivo, várias empresas compreendem que se torna necessária à implementação de um Sistema de Gestão Ambiental. Com o objetivo de apresentar diretrizes básicas para a elaboração de um Sistema de Gestão Ambiental segundo as normas ISO $14001 \mathrm{em}$ uma empresa de supermercado, o presente estudo analisou e descreveu as práticas ambientais adotadas por essa empresa, localizada na cidade de Sobral e sugeriu soluções para os problemas encontrados. A metodologia utilizada foi à pesquisa descritiva (fontes primárias) e visitas "in loco", em que o estudo foi feito com o representante da empresa, onde o mesmo respondeu a questionamentos aplicados, acompanhando as visitas, realizadas em diversos setores da empresa. Foram realizados diagnósticos ambientais, avaliando a empresa em toda a sua totalidade. Após obtenção das respostas e análises dos dados observados no local, constatou-se que a empresa não adota completamente um Sistema de Gestão Ambiental. Torna-se imprescindível que ela reduza os desperdícios e busque novas alternativas para a reutilização de determinados produtos, de água e diminuição do consumo de energia. Além de procurar incentivar a conscientização ambiental em seus colaboradores, para que estes tenham sempre como objetivo a minimização de impactos possíveis perante as atividades desenvolvidas.
\end{abstract}

Palavras-chaves: Gestão Ambiental. Empresa. Meio Ambiente.

\begin{abstract}
The issues related to the environment have gained ground within companies, is due to the interest in the financial return provided by the reuse of waste or by growing environmental awareness of its consumers, according to research by Ibope and the National Industry Confederation. They revealed that $68 \%$ of Brazilian consumers would pay more for products that not the environment. With all this in order to remain competitive in the market, many companies understand that it is necessary for the implementation of an Environmental Management System. In order to present basic guidelines for the preparation of an Environmental Management System according to ISO 14001 in a supermarket company, this study analyzed and described the environmental practices adopted by the company, located in Sobral and suggested solutions to the problems encountered. The methodology used was the descriptive research (primary sources) and visits "in loco", where the study was done with the company representative, where it answered the questions applied, following the visits carried out in various sectors of the company. Environmental diagnostics were performed, valuing the company at all its entirety. After obtaining the answers and analysis of the data observed at the site, it was found that the company adopts not quite an Environmental Management System. It is essential that it reduces waste and seek new alternatives for the reuse of certain products, water and reduced energy consumption. In addition to seeking to encourage environmental awareness in its employees so that they always have the objective to minimize potential impacts before the activities.
\end{abstract}

Keywords: Environmental Management. Company. Environment. 


\section{Introdução}

Segundo Kraemer (2003), a questão ambiental tem sido constantemente discutida em virtude do crescimento populacional, juntamente com consumismo excessivo e a degradação do meio ambiente. Essa situação é verificável pela evolução do quadro de contaminação do ar, da água e do solo em todo o mundo e pelo aumento do número de desastres ambientais. Diante disso, a crescente conscientização ambiental da sociedade aumentou a pressão sobre as empresas de que os padrões de produção e consumo atualmente são insustentáveis.

A discussão sobre os impactos que as empresas causam no meio ambiente vem alertando os consumidores sobre os efeitos negativos que esses impactos refletem em suas vidas, desde o Aquecimento Global devido a uma maior emissão de gases e trazendo com isso problemas à população, até o preço da conta de água devido a sua contaminação e diminuição deste recurso e consequentemente o seu encarecimento.

Em virtude disso, as empresas entendem que é necessária a adoção de um Sistema de Gestão Ambiental, para ajudar a melhorar a qualidade de vida da sociedade, buscando assim um lugar no mercado competitivo, já que empresas que atuam com projetos voltados a responsabilidade ambiental estão cada vez mais conquistando seu público. Juntar as práticas ambientais com a necessidade de consumo tornou-se uma estratégia de marketing para as organizações.

O sistema de Gestão Ambiental (SGA) é uma estrutura desenvolvida para que uma organização possa consistentemente controlar seus impactos significativos sobre o meio ambiente e melhorar continuamente as operações e negócios. O aumento do número de empresas certificadas, com rótulos ou selos verdes, em muitos países nos últimos anos, mostra a importância das práticas ambientais com critério definidor dos consumidores na hora de realizar suas compras. A norma ISO 14001 é uma norma aceita internacionalmente, que define os requisitos para estabelecer e operar um Sistema de Gestão Ambiental.

A "gestão ambiental empresarial" limita-se a empresas e instituições, e pode ser definida como sendo um conjunto de políticas, programas e práticas administrativas e operacionais que considerem a saúde e a segurança das pessoas, e a proteção do meio ambiente através da eliminação ou diminuição de impactos e danos ambientais decorrentes do planejamento, implantação, operação, ampliação, realocação ou desativação de empreendimentos ou atividades, incluindo-se todas as fases do ciclo de vida do produto (QUEZADA; PIERRE, 1998).

Diante dessa situação, observa-se que o SGA não é somente um diferencial, mas sim uma exigência para a empresa manter um lugar no mercado competitivo.

A empresa analisada visa tentar reduzir as despesas. Com o objetivo de apresentar diretrizes básicas para a elaboração de um Sistema de Gestão Ambiental segundo as normas ISO 14001 em uma empresa de supermercado localizada no município de Sobral-Ceará, o estudo buscou analisar as práticas ambientais adotadas, além de sugerir soluções para os problemas encontrados, mostrando a importância do sistema e suas vantagens para a empresa.

\section{Fundamentação}

\subsection{Sistema de Gestão Ambiental nas empresas}

De acordo com Valle (2002), a Gestão Ambiental consiste em um conjunto de medidas e procedimentos bem definidos que, se adequadamente aplicados, permitem reduzir e controlar os impactos produzidos por um empreendimento ao meio ambiente. No caso de empreendimentos já implantados, para que essa gestão seja bem idealizada, faz-se necessário uma Avaliação Ambiental Inicial, que irá permitir apontar problemas ambientais ocultos e colher subsídios para elaboração da Política Ambiental da organização.

Sistema de Gestão Ambiental é a parte do sistema de gestão global, que compreende estrutura organizacional, atividades de planejamento, responsabilidades, práticas, procedimentos, processos e recursos para desenvolver, implementar, atingir, analisar criticamente e manter a política ambiental. Com isso os empreendimentos certificados descobriram que gerenciamento de riscos, redução de custos, desempenho ambiental melhorado, minimização com custos energéticos e imagem corporativa, são alguns dos benefícios obtidos com a certificação (NBR ISO 14OO1, 2010).

Seiffert (2010) diz que a Gestão Ambiental é entendida como um processo adaptativo e contínuo, através do qual as organizações definem, e redefinem seus objetivos e metas relacionados à proteção do ambiente, à saúde de seus funcionários, bem como clientes e comunidade, além de selecionar estratégias e meios para atingir estes objetivos num tempo determinado através de constante avaliação de sua interação com o meio ambiente externo.

Nos estudos sobre Sistemas de Gestão Ambiental (SGA) surgiram diversos trabalhos propondo a implantação de modelos e práticas de gestão, as quais são vistas, de acordo com Guimaraes (2006), como parte das responsabilidades sociais das empresas e um diferencial para a organização.

Um dos grandes desafios nos tempos modernos é fa- 
zer com que as forças de mercado, representadas pelas variáveis ambientais legais, econômicas, tecnológicas, sociais, demográficas e físicas, protejam e melhorem a qualidade do ambiente (TACHIZAWA, 2002). As organizações precisam funcionar atendendo aos governos federal, estadual e municipal, assim como a grupos de interesses especiais. Estes componentes formam o ambiente político-legal e influenciam as tomadas de decisão por meio de leis, regulamentações e pressões políticas e sociais (CHURCHILL G; PETER J, 2000).

O consumidor consciente tem a atitude de selecionar produtos preferindo aqueles que são menos contaminantes e que são fabricados por empresas que investem na conservação ambiental. Maimon (1996) afirma que o consumidor tem ampliado a consciência ambiental, preocupando-se com a maximização dos recursos e componentes utilizados no sistema de produção e consumo, o que conduz a um consumo duradouro e contínuo. Outros autores, como Castro, Satomi e Caspani (2000), concordam que os consumidores estão cada vez mais conscientes do assunto referente às questões ambientais e acrescentam que as possibilidades de vender produtos dependem cada vez mais da conduta ambiental das empresas.

Pesquisas do Ibope e da Confederação Nacional da Indústria (CNI) revelaram que $68 \%$ dos consumidores brasileiros pagariam mais por produtos que não agredissem o meio ambiente (TACHIZAWA, 2002), o que deixa claro "que a tendência de preservação ambiental e ecológica por parte das organizações deve continuar de forma permanente e definitiva" (ANDRADE; TACHIZAWA; CARVALHO, 2002).

A atenção sobre a questão ambiental dentro da empresa e o crescimento da importância desta matéria ocorre quando a empresa percebe que esta preocupação não acarreta somente despesas, mas pode render oportunidades de negócios, melhoria da imagem organizacional (como mencionado anteriormente) e redução de custos, o que pode ser viabilizado através de programas de reaproveitamento e venda de resíduos, utilização racional de energia e aumento das possibilidades de reciclagem.

Desta forma, a importância da questão ambiental fica evidente quando acontece uma melhoria de seu desempenho ambiental, traduzida através de um ganho com relação aos aspectos ora citados (OTTMAN, 1997).

De acordo com Tocchetto (2005), algumas das práticas mais abordadas são: uso consciente da energia, água e matérias-primas; redução e tratamento de resíduos; adequação a legislação ambiental vigente; treinamentos e conscientização dos colaboradores quanto à sustentabilidade; reforçar o marketing da organização quanto a suas ações ambientais; e também, desenvolver métodos para avaliar os resultados obtidos com a implementação de um SGA.

A gestão ambiental está fundamentada em 5 princípios básicos que podem ser definidos como segue: Princípio 1: Analisar o que deve ser feito; assegurar comprometimento com o SGA e elaborar uma Política ambiental.

Princípio 2: Construir um Plano de Ação para atender aos requisitos da política ambiental.

Princípio 3: Garantir condições para o cumprimento dos objetivos e metas Ambientais e implementar as ferramentas de sustentação necessárias.

Princípio 4: Realizar avaliações qualitativas e quantitativas periódicas da conformidade ambiental da empresa.

Princípio 5: Revisar e aprimorar a política ambiental, os objetivos e metas e as ações implementadas para garantir a melhoria contínua da performance ambiental da empresa.

Atender aos princípios citados por meio de uma metodologia prática para a implementação de um SGA é garantia de minimização de impactos ambientais e, ao mesmo tempo, de melhoria de imagem da empresa no mercado (ROVERE, 2000).

Segundo Castro et al. (2004), a questão ambiental é uma realidade que com certeza faz parte das empresas modernas. E não se trata de um tardio despertar de consciência ecológica dos empresários e gestores, mas uma estratégia de negócio, porque pode indicar vantagens competitivas ao promover a melhoria contínua do desempenho ambiental da empresa. É minimizar os impactos ambientais de suas atividades e tornar suas operações ecologicamente corretas.

\subsection{Normas ISO}

Em geral a maioria dos países tem seu próprio organismo gerador de normas técnicas, embora as empresas sejam livres para adotar as que sejam de seu interesse, a não ser no caso de documentos normativos de cumprimento obrigatório, como os regulamentos técnicos.

Porém, existem normas internacionais que são adotadas por muitos países, como exemplo a ISOInternational Organization for Standardization (Organização Internacional para Normalização), uma organização não governamental com sede em Genebra-Suíça, fundada em 23/02/47, em que desenvolve Normas e Padrões Internacionais relacionadas a vários assuntos e setores.

No Brasil, é a ABNT (Associação Brasileira de Normas Técnicas) que traduz o que as normas ISOS estabe- 
lecem. O fórum credenciador é o INMETRO (Instituto Nacional de Metrologia, Normalização e Qualidade Industrial), para criação das normas técnicas nacionais no Brasil.

Em 1992, na Conferência das Nações Unidas sobre Meio Ambiente e Desenvolvimento, realizado no Rio, foi proposta para criação na ISO de um grupo especial para elaborar normas técnicas relacionadas ao meio ambiente, sendo que, em dezembro de 1996, a ABNT lançou oficialmente no Brasil as Normas da série ISO 14000, relacionadas a Sistema de Gestão Ambiental, incluindo implantação do sistema e realização de auditorias para certificação do sistema.

A Norma NBR ISO 14001 discrimina os requisitos para a implementação de um Sistema de Gestão Ambiental, que forneçam às organizações os elementos efetivos que possam ser integrados com outros requisitos gerenciais, para auxiliar no alcance das metas ambientais e econômicas.

Está evidente na sua introdução que a Norma foi escrita para ser aplicável a todos os tipos e tamanhos de organização e para se adequar às diferentes condições geográficas, culturais e sociais. Ela habilita uma organização a estabelecer e avaliar a efetividade de procedimentos para definir uma política ambiental e os objetivos a atingir suas conformidades. O intuito geral da norma é apoiar a proteção ao meio ambiente e a prevenção da poluição em equilíbrio com as necessidades socioeconômicas (ABNT, 1996a).

A ISO 14001 dispõe um guia para os requisitos do SGA tendo como base um modelo de ciclo de melhoria contínua do tipo planejar - executar - verificar - agir, ciclo PDCA (ANGELL; KLASSEN, 1999, LOKKEGAARD, 1999).

Segundo Lima (2006) este modelo é uma ferramenta usada para a aplicação das ações de controle dos processos, tal como estabelecimento da "diretriz de controle", planejamento da qualidade, manutenção de padrões e alteração da diretriz de controle, ou seja, realizar melhorias. Essas ações se dividem em quatro fases básicas que devem ser repetidas continuamente, e cada fase com várias etapas (Figura1).

I. Plan - Planejamento - Fase onde o plano é traçado. Realiza-se um diagnóstico dos problemas ambientais, econômicos e sociais encontrados na empresa e estabelecem-se as soluções para esses problemas. Nela se fixa a diretriz de controle, isto é, são definidos os itens de controle e se estabelecem metas para estes itens. Nesta etapa também, são decididas as estratégias para atingir as metas pré-estabelecidas, que podem ser procedimentos padrões, planos de controle, em resumo, uma ação ou uma sequencia de ações que resultem no

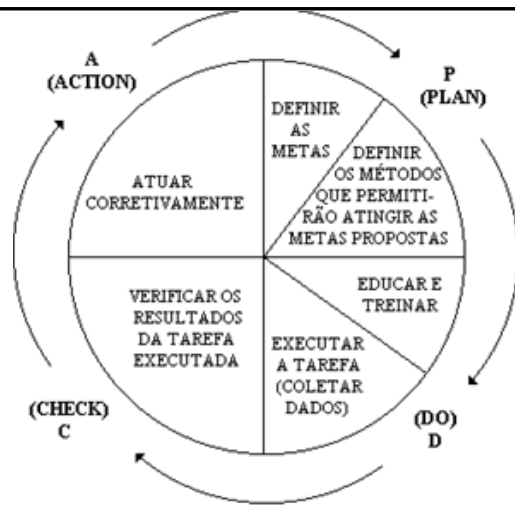

PDCA.

Figura 1: Fases do ciclo.

Fonte: Silva (2006)

cumprimento da meta. Essas ações devem ser descritas na política ambiental da empresa. (CAMPOS, 1992).

De acordo com Werkema (1995) deve-se lembrar de que a fase de planejamento é sempre a mais complexa e a que exige mais esforços. Entretanto, quanto maior o número de informações usadas, maior será a necessidade do emprego de instrumentos apropriados para coletar, processar e dispor estas informações.

II. Do - Execução - Fase onde o plano traçado na fase anterior é executado, exatamente como previsto, de acordo com o procedimento operacional padrão. Devese educar e treinar todas as pessoas envolvidas, antes do início da execução, para que haja comprometimento e a execução saia de acordo com o planejado. Neste passo, ocorre a coleta de dados, para futura verificação na fase de verificação (Check).

III.Check - Verificação - Fase onde se verifica os resultados do serviço executado e os compara com a meta planejada, a partir dos dados coletados na fase anterior. É de extrema importância o suporte de uma metodologia estatística para que se minimize a possibilidade de erros e haja economia de tempo e recursos. A avaliação dos dados desta fase indicará se o processo está de acordo com o planejado.

IV. Action - Atuação corretiva - Dispondo das análises realizadas na etapa anterior (verificação) decide-se atuar no sentido de adotar como padrão o plano proposto, no caso das metas terem sido alcançadas; ou atuar de forma corretiva sobre as causas que não permitiram que a meta fosse atingida, traçando outras metas e começando tudo novamente. Ao final dessa fase, origina-se a primeira fase do próximo PDCA (gira o ciclo, voltando ao planejamento), permitindo que se faça o processo de melhoria contínua (NEVES, 2007). 


\subsection{Etapas da implantação de um Sistema de Ges- tão Ambiental}

Implantar um sistema de Gestão Ambiental consiste numa análise dos diversos blocos do ciclo PDCA (do inglês Plan, Do, Check, Action - Planejar, Executar, Verificar, Agir). O ciclo começa pelo planejamento, em seguida a ação ou conjunto de ações planejadas são executadas, verifica-se o que foi feito, se estava conforme o planejado, constantemente e repetidamente (de forma cíclica) e realiza-se uma ação para eliminar ou ao menos mitigar defeitos no produto ou na execução da atividade (Figure2).

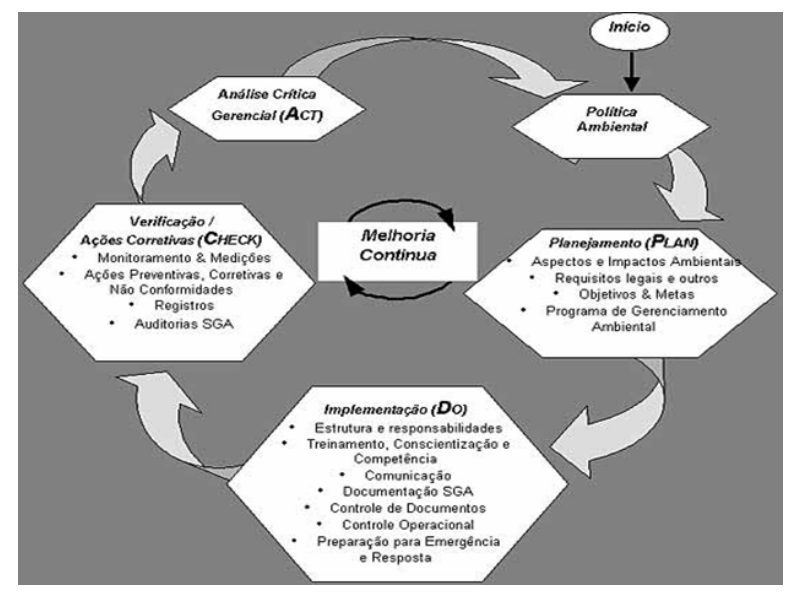

Figura 2: Etapas da Implantação do Sistema de Gestão Ambiental.

$$
\text { Fonte: Silva 2006). }
$$

\section{Materiais e Métodos}

\section{1 Área de estudo}

Serviu como base a elaboração do presente trabalho, a empresa Atacadão Hiper Frios Ltda. Cujo nome fantasia é Hipermercados Rainha, uma empresa do ramo de Varejo, que está há 18 anos no mercado, que possui três filiais, uma em Camocim e duas em Sobral.

O presente estudo foi feito na filial Rainha Nova, localizada na Avenida da Universidade, 300, Bairro Betânia, na cidade de Sobral- Ceará, dirigida pelos empresários: José Oscar Ferreira Gomes, Adília Maria Tavares Ferreira Gomes e José Sidcley Tavares Ferreira Gomes.

A Missão da empresa é comercializar produtos de qualidade com variedade a preços competitivos, com o compromisso de atender aos clientes buscando superar suas expectativas, crescendo sustentavelmente agregando mais filiais.
Tem como visão ser referência na região com excelência no atendimento e na prestação de serviço, oferecendo o prazer de estarem em nossas lojas, superando assim suas expectativas, tendo com valores, oferecer produtos e serviços de qualidade promovendo sentimento de equipe e crescimento profissional; Ser rígidos nos gastos e intolerantes com o desperdício; Manter e estimular uma relação de parceria, respeito e transparência com os fornecedores; Gerar empregos e desenvolvimento nas comunidades onde atuamos, através da responsabilidade social, tendo como metas a implantação de um SGA.

\subsection{Procedimentos Metodológicos}

Quanto à forma de abordagem, caracteriza-se como pesquisa quantitativa já que se propõe a medir o grau de percepção dos consumidores em relação à variável ambiental. De acordo com Mattar F (2001), Trujillo (2001), o método quantitativo é utilizado para a obtenção de dados de um grande número de respondentes, com o uso de escalas, na maioria das vezes numéricas, e posteriormente submetidas a análises estatísticas formais.

O estudo também enquadra-se no nível de pesquisa descritiva, pois descreve variáveis quantitativas e qualitativas, estabelecendo relações entre si (GIL, 1991). Uma das características deste tipo de pesquisa é a utilização de técnicas padronizadas de coleta de dados, como o questionário e assume, em geral, a forma de levantamento que tem como intuito, analisar criticamente o sentido das informações levantadas (CHIZZOTTI, 1995).

Os dados primários, também utilizados, são aqueles coletados pela primeira vez como parte de um estudo (GRESSLER, 2003), obtidos através da aplicação do instrumento, neste caso um questionário formado por quatro conjuntos de perguntas fechadas de múltipla escolha com alternativas pré-estabelecidas.

Com base nisso, também foram adotados as seguintes etapas técnicas:

- Foram realizadas visitas nos diversos setores da empresa observando as características da área;

- Diagnóstico do manejo dos resíduos sólidos gerados, com observações desde a geração até a disposição final dos mesmos;

- Aplicação de questionários específicos aplicados ao responsável pela empresa, contendo perguntar relacionadas à implantação de um SGA seguindo a norma ISO 14.0001. 


\section{Resultados e Discussão}

De acordo com o estudo realizado na empresa mencionada, foi caracterizada a situação ambiental da empresa diante dos resíduos gerados decorrentes das atividades dos seus principais setores.

Com os resultados, foi constatado que a empresa não adota os requisitos estabelecidos pela norma ISO 14.001 para a implantação de um SGA. Embora não possua um sistema de gestão ambiental definido, a empresa busca minimizar os desperdícios e impactos ambientais. Sendo assim, são feitas algumas soluções alternativas para a destinação dos resíduos de alguns setores reaproveitando dentro da própria empresa ou doando para outras atividades.

A empresa não possui nenhum tipo de política ambiental, no entanto, possui o Título de Responsabilidade Social, concedido pelo Sesc (Serviço Social do Comércio), por sua colaboração no Programa Mesa Brasil no combate a fome e ao desperdício de alimentos na região norte do Ceará. Além disso, recebeu um Troféu destaque empresarial no ramo dos Supermercados.

Quanto ao setor de Plataforma de recebimento de mercadorias não há um local próprio para destinação do lixo pelo fato de sua rotatividade ser alta.

No setor de Açougue os processos dos cortes de carne (Figura3) geram as sobras de carne, que são pedaços que os clientes não querem e estas são acumuladas para serem moídas e utilizadas na fabricação de linguiça caseira dentro do próprio setor. As sobras das desossas, ou seja, alguns pedaços de carnes e ossos são doados para o Programa Mesa Brasil, onde um caminhão do SESC recolhem esses materiais duas vezes por semana.

No setor de Hortifrúti/FLV (Frutas, Legumes e Verduras), os funcionários foram treinados para fazer a "limpeza" das verduras antes de colocá-las para a exposição (Figura4), onde o material com aparência desagradável é removido (retirada da 'casca'). Sendo assim, este resto de material orgânico é separado, para ser recolhido e enviado diariamente para a fazenda de um dos diretores do supermercado, onde serve de alimento para a criação de porcos.

No setor de Frios e Laticínios, as sobras de fatiamento de queijo e presunto do setor de frios (Figur:5) e laticínios são encaminhadas para o setor de padaria, onde estas são utilizadas como recheio no preparo dos salgados vendidos no supermercado.

No setor da Padaria são utilizados fornos industriais que consomem muita energia. Então a produção pode ser feita alternadamente, ou seja, enquanto um forno funciona o outro permanece desligado, tentando assim fazer a minimização dos custos de energia. No caso da modelagem de bolos, sempre são geradas algumas

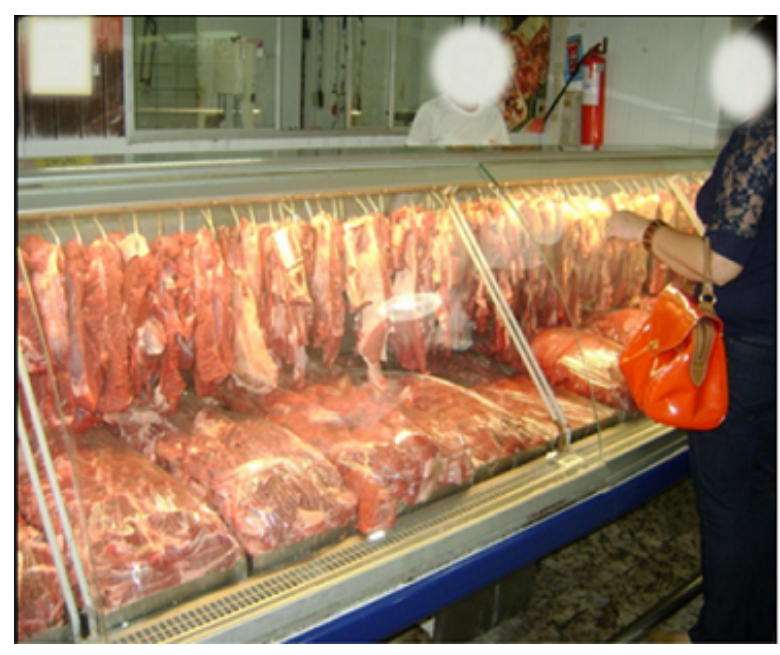

Figura 3: Área externa do setor de açougue.

Fonte: Autores (2014).

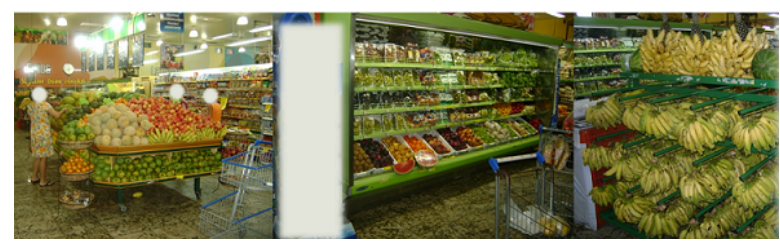

Figura 4: Área externa do setor de Hortifrúti/FLV.

Fonte: Autores (2014).

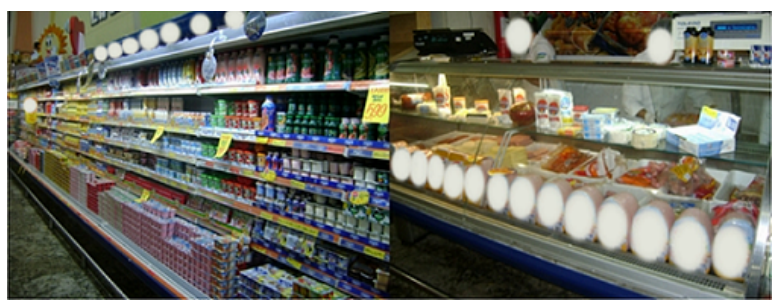

Figura 5: Área externa do setor de Frios e Laticínios.

Fonte: Autores (2014). 
sobras e estas podem ser aproveitadas no preparo de algumas sobremesas.

No setor de Rotisseria, mais conhecido como restaurante há a segregação dos resíduos orgânicos dos inorgânicos, além da coleta do óleo utilizado no preparo das frituras e das refeições, onde este é armazenado para ser doado e posteriormente utilizado na fabricação de sabão.

Em relação às câmaras frias, para armazenagem de carnes, frutas, verduras, frios e laticínios, no início eram abertos (o que gerava um maior consumo de energia). Entretanto, foram colocadas cortinas de PVC para reduzir a saída do ar frio e consequentemente diminuírem o consumo de energia.

Há ainda a separação e prensagem do papelão, além da coleta de sacos plásticos, onde a cada dez dias, estes são encaminhados para uma empresa da cidade de Fortaleza que compra esse material do supermercado.

Contudo, observou-se que a direção do supermercado preocupa-se com a questão de desperdícios visando apenas o lado financeiro, sem visar os benefícios ambientais. Tal fato foi constatado por meio das observações nas áreas visitadas e também pelas citações da direção do supermercado salientando a preocupação com a estabilidade financeira devido preservação do capital e manter-se sempre competitivo diante da concorrência local.

Foi realizado um levantamento em reais $(\mathrm{R} \$)$ dos custos referentes aos desperdícios nos cinco primeiros meses dos anos de 2013 e 2014 (Tabel/1), observandose uma redução obtida devido à iniciativa de minimização da geração e reutilização de resíduos, como mostrado no (Gráfico 1). Os cálculos foram efetuados com base na mudança das atividades relacionadas aos setores como, por exemplo, troca de compra de sacolas plásticas para acomodação de resíduos e inserindo-os em outros depósitos mais duráveis (bombonas plásticas, dentre outros), diminuição de banners e material publicitário, realmente efetivar o acompanhamento de cada gasto (em 2013 esse levantamento não era feito com tanta frequência ou eficiência), outro fator levado em consideração foi o encaminhamento de resíduos orgânicos para estações de compostagem, antes pagava-se um valor específico para os coletores municipais encaminharem para a disposição final.

Apesar da tentativa de minimizar os desperdícios, mesmo tendo-se conseguido uma significativa redução no que se refere aos gastos financeiros se faz necessário o acompanhamento integral de todos os processos para que o sistema continue tendo efeitos positivos.

Com a implantação de um Sistema de Gestão Ambiental são esperados fatores que venham trazer ganhos
Tabela 1: Custos em reais dos desperdícios.

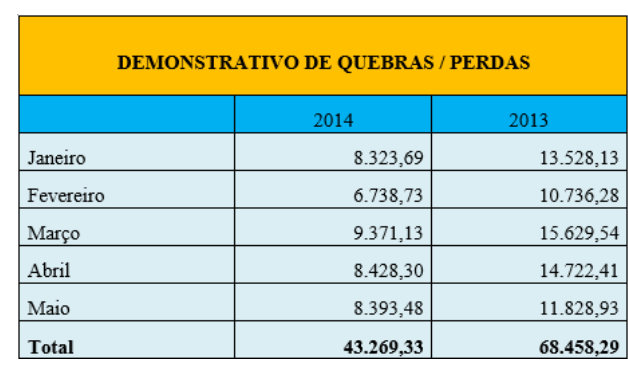

Fonte: Autores (2014).

Tabela 2: Demonstrativo de custos relacionados aos resíduos nos anos de 2013/ 2014

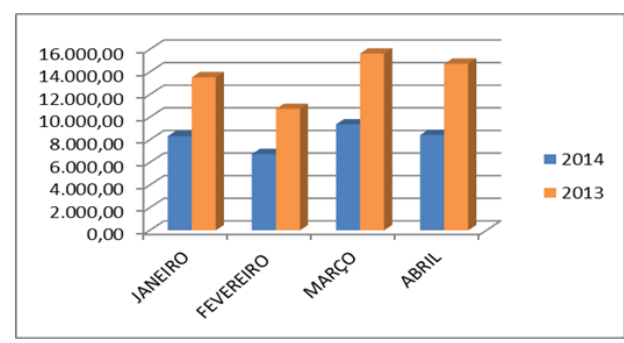

Fonte: Autores (2014).

importantes para a organização quanto para o meio ambiente, tais como:

- Redução de desperdícios (economizar em transporte e armazenamento, diminuir, em alguns casos, os valores dos prêmios de seguro e reduzir gastos com segurança e proteção à saúde).

- Tecnologias novas (instalação para redução ou prevenção da geração de resíduos; modificação de equipamentos, para estimular a recuperação ou a reciclagem; aumento da eficiência operacional de equipamentos, para a redução no consumo de energia);

- Possibilidade de demonstrar consciência ambiental ao mercado (competitividade);

- Boa reputação nos órgãos ambientais, na comunidade e ONGs;

- Possibilidade de obter financiamento a taxas reduzidas ou atendimentos a requisitos dos bancos.

Depois de observar as vantagens de se implantar um SGA surge o interesse dos empresários por obter esse sistema, mas sua maior preocupação seriam os custos 
relativos ao processo. Devem-se analisar os resultados a longo prazo, pois estes além de recuperar os custos do processo de implantação, ainda geram lucro para a empresa.

A empresa não faz uso do sistema de coleta seletiva e gerenciamento de resíduos sólidos, assim observando a necessidade de contratar um gestor ambiental para implantar um sistema de gestão ambiental, e em consequência uma política ambiental e um gerenciamento de resíduos sólidos, para minimização, reutilização, reaproveitamento, campanhas educativas entre os funcionários, armazenamento correto entre outros fatores. Diante das respostas e discussões, notou-se a demanda de implantação um sistema de gestão ambiental na empresa Hipermercado Rainha.

A partir de todo o exposto são apresentadas a seguir, as diretrizes mínimas a serem consideradas no Sistema de Gestão Ambiental para a empresa, nas quais, foram apresentadas aos donos do Hipermercado, nos quais, gentilmente autorizam a execução da pesquisa e aguardavam dos pesquisadores um retorno do que foi analisado. As diretrizes para uma empresa implementar ou aperfeiçoar um SGA incluem conforme a ISO 14001:

- Reconhecer que a gestão ambiental está entre as prioridades da corporação.

- Estabelecer e manter diálogo com as partes interessadas, internas e externas.

- Determinar as obrigações legais e aspectos ambientais associados com atividades da organização, seus produtos e serviços.

- Desenvolver o compromisso da gerencia e dos funcionários para com a proteção do ambiente, com definição clara das responsabilidades.

- Encorajar o planejamento ambiental do início ao fim do ciclo de vida do produto ou do processo.

- Prover recursos apropriados e suficientes, incluindo treinamento para alcançar, numa base ambiental contínua, os níveis de desempenho pretendidos.

- Avaliar o desempenho ambiental confrontando-o com a política e com os objetivos e metas, visando melhoria quando apropriado.

- Estabelecer um processo de gerenciamento para analisar criticamente e auditar o SGA, e para identificar oportunidades de melhoria do sistema e do desempenho ambiental resultante.
Estas diretrizes podem ser usadas por organizações de qualquer tamanho. De qualquer maneira, a importância de pequenas e médias empresas tem sido cada vez mais reconhecida pelos governos e pelo mercado competitivo. Estas diretrizes reconhecem e conciliam as necessidades da empresa.

\section{Conclusão}

O presente estudo mostrou as medidas utilizadas na implantação de um Sistema de Gestão Ambiental por uma empresa de Supermercados.

Foi constado que a empresa não adota os procedimentos definidos pela ISO 14.001 para a implantação de um SGA. Entretanto, adota algumas medidas que minimizam os impactos ambientais gerados no estabelecimento tais como reaproveitamento dos resíduos gerados no próprio estabelecimento ou doando a outras instituições.

Considerando as medidas mitigadoras utilizadas pela gerencia do supermercado, avaliou-se que independentemente da segregação, que já é realizada, a organização poderia investir mais na adoção de um SGA, já que este poderia além de atingir um dos objetivos da empresa (que seria a redução de custos relacionados aos desperdícios), seria também um investimento em treinamentos com os funcionários, disseminando assim conhecimento e transparecendo para a comunidade a sua preocupação com o meio ambiente, o que resultaria em um atrativo para os consumidores, já que a responsabilidade ambiental está cada vez mais presente no dia a dia.

Foram apresentadas algumas diretrizes para a implantação do SGA. As diretrizes apresentadas servem para direcionar a iniciativa de implantação de um sistema de gestão ambiental, mostrando as necessidades atuais que requerem a preocupação da empresa, as medidas a serem implementadas para atingir os objetivos estipulados e obter resultados em longo prazo e a manutenção destes.

\section{REFERÊNCIAS}

ABNT, A. B. D. N. T. Nbr iso 14001:sistemas de gestão ambiental-especificação e diretrizes para uso. Rio de Janeiro, 1996a.

Nbr iso 14001:sistemas de gestão ambiental diretrizes gerais sobre princípios, sistemas e técnicas de apoio. Rio de Janeiro, $1996 \mathrm{~b}$.

ANDRADE, R. O. B.; TACHIZAWA, T.; CARVALHO, A. B. Gestão ambiental: enfoque estratégico aplicado 
DIRETRIZES BÁSICAS PARA ELABORAÇÃO DE SISTEMA DE GESTÃO AMBIENTAL EM EMPRESA DE SUPERMERCADOS

ao desenvolvimento sustentável. 2ed. São Paulo:

Pearson Education do Brasil, 2002.

ANGELL, L. C.; KLASSEN, R. D. Integrating environmental issues into the mainstream: an agenda for research in operations management. Journal of Operations Management, v. 17, n. 5, p. 575-598, Aug 1999.

BERVIAN, P. A.; CERVO, A. L. Metodologia científica para o uso de estudantes universitários. 4ed. São Paulo: McGraw-Hill do Brasil, 1996.

CAMPOS, V. F. Controle da qualidade total (no estilo japonês). Belo Horizonte: Fundação Christiano Ottoni, 1992.

CASTRO, G.; SATOMI, L.; CASPANI, E. Empresas fazem opção pelo verde. Gazeta Mercantil. Ano 5, n. 231 , out. 2000 .

CASTRO, N.; SETTI, A. A.; GIORGONIO, A.; FARIA, S.; REEBERG, J. H. A questão ambiental e as empresas. Brasília: SEBRAE, 2004.

CHIZZOTTI, A. Pesquisa em ciências humanas e sociais. São Paulo: Cortez, 2ed, 1995.

CHURCHILL G, A.; PETER J, P. Marketing: criando valor para os clientes. São Paulo: Saraiva, 2000.

GIL, A. C. Como elaborar projetos de pesquisa. 3ed. São Paulo: Atlas, 1991.

GRESSLER, L. A. Introdução à pesquisa: projetos e relatórios. São Paulo: Edições Loyola, 2003. 295 p.

GUIMARAES, C. Práticas de gestão ambiental aplicadas em serviços de hotelaria: um estudo de caso. 2006.

KRAEMER, M. E. Gestão Ambiental: Um Enfoque no Desenvolvimento Sustentável. Itajaí: , 2003. Disponível em: <http://www.gestiopolis.com/canales3/ ger/gesamb.htm>. Acesso em: 23 mar, 2014.

LIMA, R. d. A. Como a relação entre clientes e fornecedores internos à organização pode contribuir para a garantia da qualidade: o caso de uma empresa automobilística. Ouro Preto: UFOP, 2006.

LOKKEGAARD, K. E. Iso 14031 used as a tool in iso 14001 or as an alternative for a simple ems. Greener Management International, n. 28, p. 79-89, 1999.

MAIMON, D. Passaporte verde: gestão ambiental e competitividade. Rio de Janeiro: Qualitymark, 1996.
MATTAR F, N. Pesquisa de marketing. edição compacta. 3.ed. São Paulo: Atlas, 2001.

NEVES, T. F. Importância da utilização do ciclo PDCA para garantia da qualidade do produto em uma indústria automobilística, 72f. Monografia (Graduação Engenharia de Produção) - Departamento de Engenharia de Produção. Universidade Federal de Juiz de Fora, Minas Gerais: , 2007.

OTTMAN, J. A. Marketing verde: desafios e oportunidades para a nova era do marketing. São Paulo: Makron Books, 1997.

QUEZADA, R.; PIERRE, C. V. Gestão ambiental empresarial, 1o, 2o, 3o e 4o módulos. SEBRAE/RJ, Cidade Universitária, UFRJ, Rio de Janeiro, nov 1998.

ROVERE, E. L. L. Manual de auditoria ambiental. Rio de Janeiro: Quality Mark, 2000.

SEIFFERT, M. E. B. ISO 14001 Sistemas de gestão ambiental: Implantação objetiva e econômica, $3 e d .4$. Reimpr. São Paulo: Atlas, 2010.

SILVA, J. A. d. Apostila de controle da qualidade. Juiz de Fora: UFJF, 2006.

TACHIZAWA, T. Gestão ambiental e responsabilidade social corporativa: estratégias de negócios focadas na realidade brasileira. São Paulo: Atlas, 2002.

TOCCHETTO, M. R. L. Gerenciamento de resíduos sólidos industriais. Universidade Federal de Santa Maria., 2005.

TRUJILLO, V. Pesquisa de mercado qualitativa \& quantitativa. São Paulo: Scortecci, p. 100, 2001.

VALLE, C. E. Qualidade Ambiental-ISO 14.000. : Editora Senac São Paulo, 2002.

WERKEMA, M. C. C. As ferramentas da qualidade no gerenciamento de processos. : Belo Horizonte: Fundação Christiano Ottoni, UFMG, 1995. 